\title{
Enterococcus faecium L-15 Cell-Free Extract Improves the Chondrogenic Differentiation of Human Dental Pulp Stem Cells
}

\author{
Hyewon Kim ${ }^{1}{ }^{\oplus}$, Sangkyu Park ${ }^{1,2}$, Kichul Kim $^{1}$, Seockmo Ku ${ }^{3}{ }^{\circledR}$, Jeongmin Seo ${ }^{1,2, *}$ and \\ Sangho Roh $1, *(1)$ \\ 1 Cellular Reprogramming and Embryo Biotechnology Laboratory, Dental Research Institute, BK21, \\ Seoul National University School of Dentistry, Seoul 08826, Korea; khw0063@naver.com (H.K.); \\ good0039@hanmail.net (S.P.); fpdh0839@naver.com (K.K.) \\ 2 Biomedical Research Institute, NeoRegen Biotech Co., Ltd., Gyeonggi-do 16614, Korea \\ 3 Fermentation Science Program, School of Agriculture, College of Basic and Applied Sciences, \\ Middle Tennessee State University, Murfreesboro, TN 37132, USA; seockmo.ku@mtsu.edu \\ * Correspondence: jminseo@gmail.com (J.S.); sangho@snu.ac.kr (S.R.); Tel.: +82-2-880-2333 (J.S. \& S.R.)
}

Received: 29 November 2018; Accepted: 28 January 2019; Published: 31 January 2019

\begin{abstract}
Hyaline cartilage is a tissue of very low regenerative capacity because of its histology and limited nutrient supply. Cell-based therapies have been spotlighted in the regeneration of damaged cartilage. Dental pulp stem cells (DPSCs) are multipotent and are easily accessible for therapeutic purposes. In human gastrointestinal tracts, Enterococcus faecium is a naturally occurring commensal species of lactic acid bacteria. In this work, the human DPSCs were differentiated into chondrocytes using a chondrogenic differentiation medium with or without L-15 extract. We observed that chondrogenic differentiation improved in an E. faecium L-15 extract (L-15)-treated DPSC group via evaluation of chondrogenic-marker mRNA expression levels. In particular, we found that L-15 treatment promoted early-stage DPSC differentiation. Cells treated with L-15 were inhibited at later stages and were less likely to transform into hypertrophic chondrocytes. In L-15-treated groups, the total amount of cartilage extracellular matrix increased during the differentiation process. These results suggest that L-15 promotes chondrogenic differentiation, and that L-15 may be used for cartilage repair or cartilage health supplements. To our knowledge, this is the first report demonstrating the beneficial effect of L-15 treatment on chondrogenic differentiation.
\end{abstract}

Keywords: dental pulp stem cells (DPSCs); lactic acid bacteria; Enterococcus faecium; chondrogenic differentiation

\section{Introduction}

Hyaline cartilage is composed of chondrocytes and extracellular matrix, including collagen, proteoglycans, and hyaluronic acid. The tissue is commonly damaged by aging, trauma, inflammation, and degenerative disease [1]. Because of its avascular and aneural character (which makes it difficult to regenerate when damaged), cell-based therapy is an optimal treatment. This is seen when autologous chondrocytes are implanted in a damaged area [1,2]. In clinical cases, autologous chondrocyte implantation (ACI) is unlikely to cause immune rejection and is effective in treating cartilage defects $[3,4]$. However, the number of chondrocytes in the body is low, and there are limited chondrocytes available for use [5]. Due to the substantial limitations of ACI, mesenchymal stem cells (MSCs) are getting spotlight as a cell source for cartilage repair [1,6,7].

Stem cells are suitable for tissue regeneration because they can self-renew and differentiate into various types of cells [6]. Dental pulp stem cells (DPSCs) are neural crest-derived mesenchymal stem 
cells that can be obtained from the pulp tissue of the tooth [8]. Unlike isolating bone marrow-derived mesenchymal stem cells, DPSCs can be obtained by non-invasive methods because the stem cells are present in extracted teeth [9]. As multipotent stem cells, DPSCs are capable of differentiating into adipogenic, osteogenic, chondrogenic, and myogenic cells, and they have high proliferation rates [10]. Moreover, DPSCs have the potential for use in cell-based therapies for type 1 diabetes, neurological diseases, and immunodeficiency diseases [11-13].

Probiotics comprise a variety of microbial species found in the mammalian gastrointestinal tract. Lactic acid bacteria (LAB) are mainly used as probiotic strains. They have positive effects on human health, including protection of the host from infection through immunomodulatory effects on homeostasis, and include Lactobacilli, Streptococci, Bifidobacteria, and Enterococci species [14]. Among these LAB varieties, Enterococcus faecium has been shown to improve intestinal health and reduce serum cholesterol levels $[15,16]$. It is a mass-produced microorganism for commercial application in nutraceutical and food supplement markets. Various research groups have conducted studies on the effects of LAB on adipogenic and osteogenic differentiation $[17,18]$. Recently, it was reported that E. faecium has antioxidant and anti-inflammatory effects, both in vitro and in vivo $[19,20]$. E. faecium has not been reported to have side effects, so it may be useful for the treatment and prevention of cartilage defects. Moreover, to our knowledge, there are no reports on the effects of $\mathrm{LAB}$ on cartilage differentiation. In this study, we investigated the impact of E. faecium L-15 extract on chondrogenic differentiation.

\section{Results}

\subsection{Human DPSC Characterization and Isolation}

Although various cell types were initially observed, homogeneous populations of fibroblast-like cells were observed after passage 3 (Figure 1a,b). To investigate the properties of human DPSCs (hDPSCs), cells were analyzed by fluorescence-activated cell sorting (FACS). Dental pulp tissues were obtained from two different donors and FACS analysis was conducted with each sample. At passage 4, the hDPSCs expressed high levels of MSC markers (i.e., CD10 (92.48\%), CD29 (100\%), CD44 (100\%), CD73 (100\%), CD90 (100\%) and CD105 (88.13\%)), but low levels of hematopoietic and endothelial stem cell markers (i.e., CD14 (20.11\%), CD31 (0.53\%), CD34 (1.24\%), and CD45 (0.82\%)) (Figure 1c,d and Table S1). At passage 8, the hDPSCs showed similar surface marker expression to that at passage 4 (Figure S1 and Table S2). Therefore, passage 4-8 cells were used for chondrogenic differentiation.
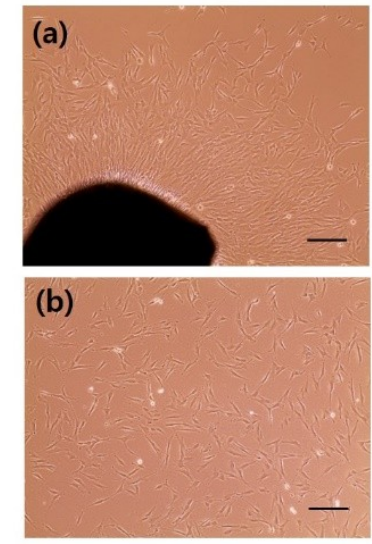

(c)
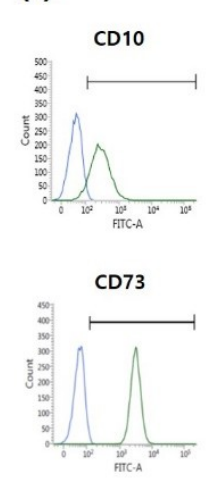
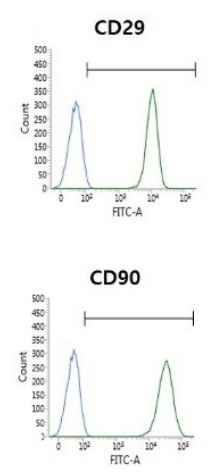
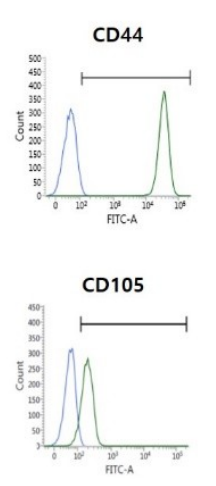

(d)
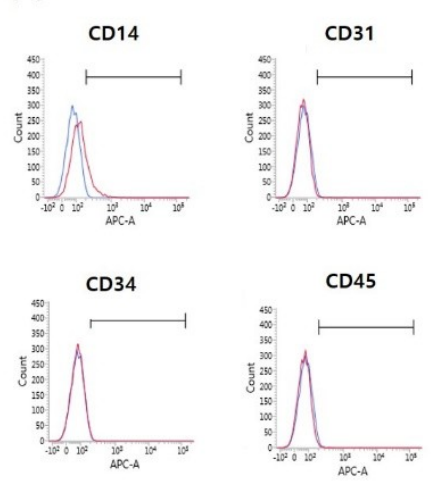

Figure 1. (a) The morphology of primary supernumerary tooth-derived human dental pulp stem cells (hDPSCs). (b) In vitro cultured hDPSCs at passage 3. The scale bar is $100 \mu \mathrm{m}$. (c) Characterization of hDPSCs at passage 4 by fluorescence-activated cell sorting (FACS) analysis. Mesenchymal stem cell markers (92.48\% CD10; 100\% CD29; 100\% CD44; 100\% CD73; 100\% CD90; 88.13\% CD105) were highly expressed in hDPSCs compared to (d) only a small degree of hematopoietic and endothelial marker expression (20.11\% CD14; 0.53\% CD31; 1.24\% CD34; 0.82\% CD45). 


\subsection{Effect of E. faecium L-15 Extract (L-15) on hDPSC Viability}

The effect of L-15 extract on cell viability was assessed by the Water-soluble tetrazolium salt (WST) assay. L-15 extract was prepared at 10, 25, 50, 100, 200, and $300 \mu \mathrm{g} / \mathrm{mL}$. As shown in Figure 2, hDPSC viability was significantly decreased by treatments of $100 \mu \mathrm{g} / \mathrm{mL}$ or more. This suggested that an L-15 extract concentration of $50 \mu \mathrm{g} / \mathrm{mL}$ was safe, and this concentration was used for subsequent experiments.

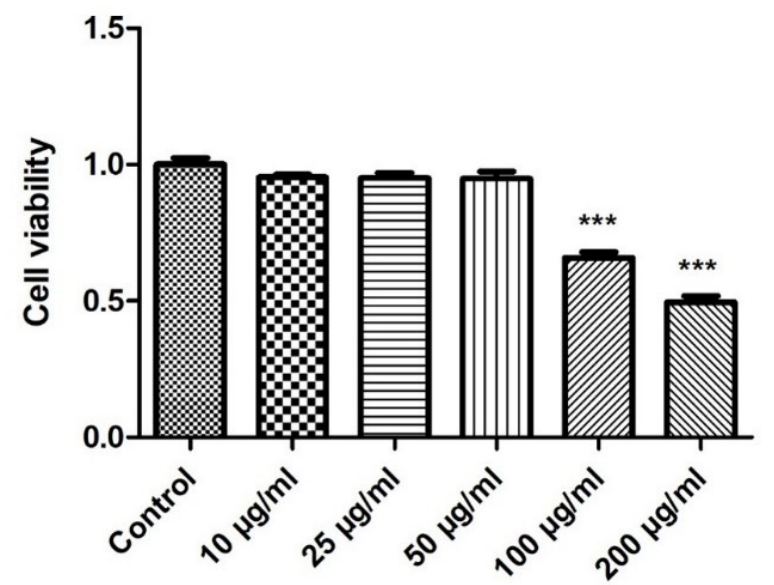

Figure 2. Water-soluble tetrazolium salt (WST) assays were used to detect hDPSC viability on exposure to L-15 extract $(n=3)$. Error bars represent mean \pm S.D. ${ }^{* * *} p<0.01$, one-way ANOVA followed by Dunnett's post hoc test was used.

\subsection{L-15 Extract Promotes Early-Stage Chondrogenic Differentiation}

The hDPSCs were differentiated into chondrocytes using chondrogenic differentiation medium with or without L-15 extract. Total mRNA was extracted from the control group (L-15 extract-free) and the L-15 extract-treated group (LET) at days 3, 5, 7, 10, and 14 to observe gene expression changes (Figure 3). Using quantitative real-time PCR, we examined the expression of early-stage chondrogenic markers (i.e., $S R Y$ (sex-determining region Y), box 9 (SOX9), aggrecan $(A C A N)$, and collagen type 2 alpha 1 (COL2A1)) and late-stage chondrogenic markers (i.e., collagen type 10 alpha 1 (COL10A1), runt-related transcription factor 2 (RUNX2), and matrix metallopeptidase 13 (MMP13)). The expression of SOX9 increased until day 10, then decreased at day 14 in the control group. The expression of COL2A1 and ACAN increased until day 14 in the control group. Expression levels of SOX9, COL2A1, and $A C A N$ were significantly higher in the LET group than the control group for 14 days. Specifically, SOX9 and COL2A1 showed significantly higher expression than the control group at days 5, 7, 10, and 14. ACAN showed significantly higher expression than the control group at days 5, 7, and 10. SOX9, $A C A N$, and COL2A1 exhibited the highest differences between the two groups on day 5 . The control group expression of COL10A1, RUNX2, and MMP13 increased during the differentiation process. In the LET group, COL10A1, RUNX2, and MMP13 showed significantly higher expression than the control group on day 5. MMP13 (a late-stage chondrogenic marker and also an extracellular matrix degradation marker) was elevated in the LET group versus the control group at day 5, but significantly decreased in the LET group by day 7. 


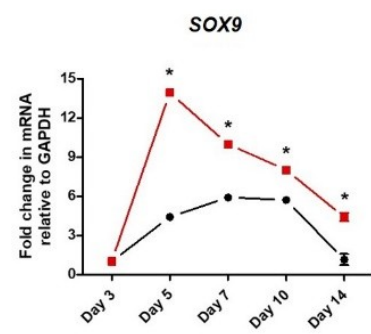

COL10A1

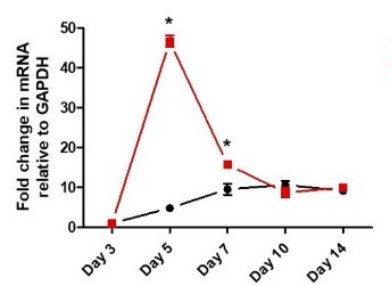

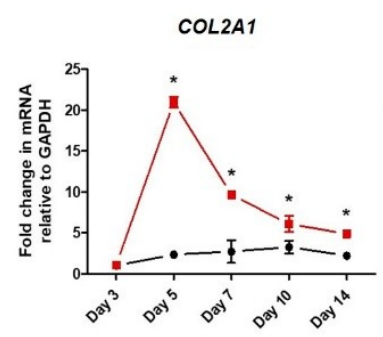

RUNX2

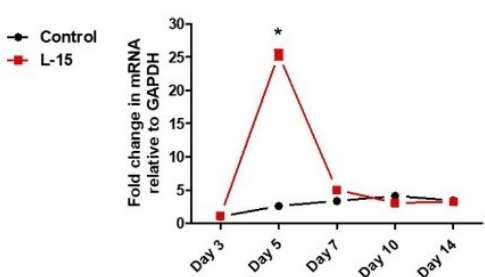

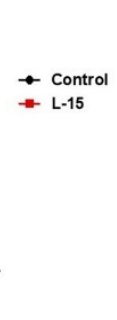

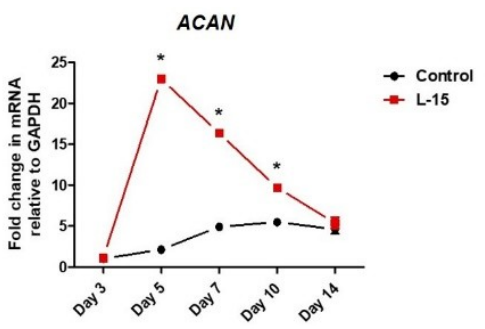

MMP13

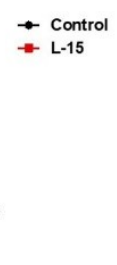

Figure 3. Total RNA was prepared from culture days 3, 5, 7, 10, and 14. The expression of early-stage chondrogenic marker genes (SOX9,COL2A1, and ACAN) and late-stage chondrogenic marker genes (COL10A1, RUNX2, and MMP13) was analyzed by qRT-PCR. GAPDH was used for normalization $(n=3)$. Error bars represent mean \pm S.D. ${ }^{*} p<0.05$, two-way ANOVA was used.

\subsection{L-15 Extract Promotes ECM Formation during Chondrogenic Differentiation}

The expression level of GAG, a marker specific to the extracellular matrix of chondrocytes, was quantitatively analyzed. GAG accumulation in the control and LET groups tended to increase over 10 days. GAG accumulation was significantly and consistently higher in the LET group than the control group, but the difference between the two groups decreased over time (Figure 4). Alcian blue staining was performed to assess accumulation of proteoglycan (e.g., GAG and hyaluronic acid) levels in chondrogenic-differentiated cells. Stained samples were quantified by spectrophotometry (Figure 5a). Similar to the results with GAG assay, the alcian blue staining intensity increased steadily in both groups over 14 days and was significantly higher in the LET group versus the control group (Figure 5b).

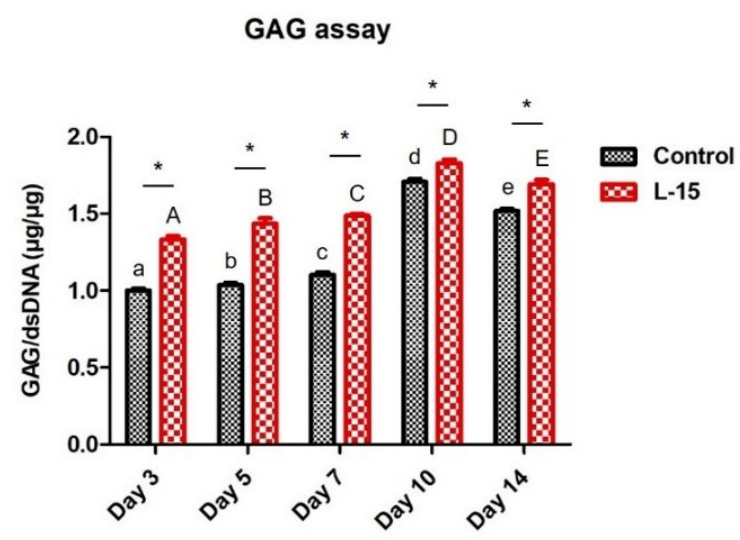

Figure 4. Total glycosaminoglycan (GAG) determinations were performed using the Blyscan ${ }^{\mathrm{TM}}$ glycosaminoglycan assay (Biocolor, Carrickfergus, UK) in human DPSCs cultured in the presence or absence of $50 \mu \mathrm{g} / \mathrm{mL} \mathrm{L-15}$ extract $(n=3)$. The amounts of GAG were normalized by the amount of DNA contained in each sample. Error bars represent mean \pm S.D. A, B, C, D, and E values of different superscripts indicate significant difference between LET groups and a, b, c, d, and e values of different superscripts indicate significant difference between control groups ( $\left.{ }^{*} p<0.05\right)$; two-way ANOVA was used. 
(a)

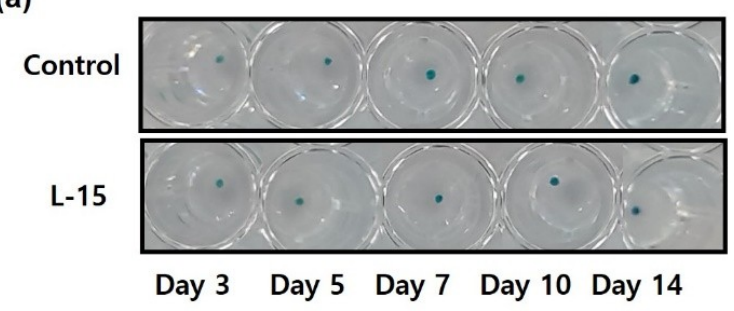

(b)

Quantification of alcian blue staining

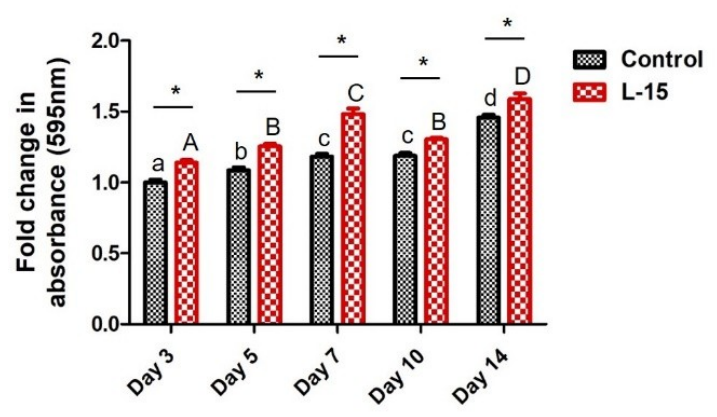

Figure 5. (a) Alcian blue staining of the control and L-15 extract-treated groups. (b) Quantitative measurements of alcian blue staining $(n=3)$. Error bars represent mean \pm S.D. A, B, C, and D values of different superscripts indicate significant difference between LET groups and $a, b, c$, and d values of different superscripts indicate significant difference between control groups $\left({ }^{*} p<0.05\right)$; two-way ANOVA was used.

\section{Discussion}

Hyaline cartilage defects do not directly impact human survival, but they severely affect quality of life. As the elderly population is increasing in many countries, the number of patients with cartilage defects will continue to rise [1]. However, the current treatments for cartilage defects are limited. To provide symptomatic relief, new fundamental therapies are needed [21]. Stem cell-based therapies for cartilage regeneration have been widely studied in recent years $[5,22,23]$. In this study, we showed that early-stage chondrogenic markers (SOX9, COL2A1, and ACAN) and late-stage chondrogenic markers (COL10A1, RUNX2, and MMP13) are expressed during chondrogenic differentiation of human DPSCs. When hDPSCs were cultured in chondrogenic differentiation medium with L-15 extract, the expression of early-stage chondrogenic markers tended to be higher in the LET group than in the control group. The initial expression of the late-stage chondrogenic markers COL10A1 and RUNX2 was significantly higher in the LET group than in the control group. However, this increased expression gradually decreased to a level similar to the control group.

Hypertrophy is induced in the late stages of in vitro chondrogenic differentiation and is one of the problems that still has to be overcome in cell-based therapy for cartilage repair [24]. Once a chondrocyte enters the hypertrophic state, it is difficult for it to return to normal chondrocyte because hypertrophic chondrocytes secrete MMPs and do not maintain chondrocyte homeostasis [25]. MMP13, a late-stage chondrogenic marker, is the main enzyme responsible for cartilage degradation [26]. Compared to other MMP family members, MMP13 is specific to the extracellular matrix degradation of connective tissue, cartilage collagen, and proteoglycans [26]. A variety of clinical studies have reported that patients with cartilage destruction have high MMP13 expression [27,28]. Many research groups have also found that MMP13-overexpressing transgenic mice display a cartilage-destruction phenotype, which suggests that increased MMP13 is associated with cartilage degradation $[29,30]$. Interestingly, the expression of MMP13 was increased by treatment of L-15 extract during the early stages. On the other hand, the expression of MMP13 in the LET group decreased significantly during the later stages. Although the expression of late-stage chondrogenic markers was upregulated during the early stages, 
it was not hypertrophic state since the early-stage chondrogenic markers maintained higher expression levels during the period of differentiation, and the expression of MMP13 had significantly lower levels during the later stages in the LET group than in the control group [31]. Cartilage ECM provides structural and biochemical support to chondrocytes and consists of collagen, aggrecan, and networks of proteoglycans which are composed of GAGs and hyaluronic acid [32]. Recently, several studies have reported that the efficiency of chondrogenic differentiation is enhanced by using collagen membranes or a hyaluronic acid and cartilage ECM $[33,34]$. In this study, we found that GAG increased during the later stages of chondrogenic differentiation. The LET group accumulated more GAG than the control group. The quantification of proteoglycans (e.g., GAG and hyaluronic acid) using alcian blue staining similarly verified chondrocyte differentiation. In summary, this study examined the effect of an L-15 extract on chondrogenic cell differentiation. We found that the L-15 extract initially promoted chondrogenic differentiation and subsequently inhibited the expression of the extracellular matrix degradation enzyme. The L-15 extract promoted chondrogenic differentiation by increasing certain extracellular matrix components (e.g., GAG). E. faecium is a type of LAB present in the human gastrointestinal tract and commonly used to produce fermented meat or dairy products $[35,36]$. Several groups have used LAB to induce adipogenic or osteogenic differentiation [37,38]. However, this is the first study to apply LAB to induce chondrogenic differentiation and demonstrate the beneficial effect of E. faecium L-15 in chondrogenic differentiation.

\section{Materials and Methods}

\subsection{Preparation of the E. faecium Extract}

The E. faecium L-15 strain (KCTC13498BP) was used for this study and was obtained from NeoRegen Biotech (Suwon, Gyeonggi-do, Korea). This strain was originally isolated from a traditional Korean rice-fermented food containing flatfish. The L-15 strain was cultured in tryptic soy broth (TSB; Hardy Diagnostics, Santa Maria, CA, USA) and incubated for $18 \mathrm{~h}$ at $35^{\circ} \mathrm{C}$. The cultured L-15 strain was harvested, washed three times in phosphate-buffered saline (PBS), and resuspended in double-deionized water $\left(\mathrm{ddH}_{2} \mathrm{O}\right)$. The washed E. faecium was sonicated (Sonics, Stratford, CT, USA) on ice for $30 \mathrm{~min}$. To remove the cellular debris, it was centrifuged at $12,000 \times \mathrm{g}$ for $10 \mathrm{~min}$. The supernatant was passed through a $0.45 \mu \mathrm{m}$ filter and frozen at $-80^{\circ} \mathrm{C}$ overnight. It was then freeze-dried and reconstituted with PBS before use.

\subsection{Isolation and Expansion of Human Dental Pulp Stem Cells (hDPSCs)}

The study was conducted in accordance with the Declaration of Helsinki, and the protocol has been approved by the Institutional Review Board (IRB, number S-D20180004, 30 March 2018) at Seoul National University School of Dentistry. Informed consent was obtained from parents of all subjects prior to sample collection. Human maxillary central supernumerary teeth $(n=2)$ were extracted from children at the Dental Hospital of Seoul National University in accordance with the guidelines provided by the IRB. The hDPSC primary culture process followed our laboratory protocol. The extracted teeth were briefly cut around the cemento-enamel junction using a cutting disk. The pulp tissue was exposed and gently separated from the crown. The pulp tissue was minced into $1 \mathrm{~mm}^{2}$ pieces with a scalpel blade and transferred into 12-well culture dishes. The cells were then grown in Minimum essential medium eagle $-\alpha$ modification ( $\alpha$-MEM; Corning, Rochester, NY, USA) supplemented with $10 \%$ fetal bovine serum (FBS; PAN-Biotech, Bayern, Germany) and incubated in a $37{ }^{\circ} \mathrm{C}$ incubator with $5 \%$ $\mathrm{CO}_{2}$. The culture medium was replaced every three days. The cells from the different donors were cultured separately.

\subsection{Characterization of hDPSCs by Fluorescence-Activated Cell Sorting (FACS)}

At passage 4 , the hDPSCs were detached and resuspended in ice-cold PBS containing 5\% FBS. The cells were incubated on ice for $30 \mathrm{~min}$ with monoclonal antibodies against CD10-fluorescein isothiocyanate 
(FITC), CD29-Alexa 488, CD44-FITC, CD73-FITC, CD90-FITC, CD105-FITC, CD14-allophycocyanin (APC), CD34-Alexa 647, CD45-APC, and CD31-APC. All antibodies were purchased from Biolegend (San Diego, CA, USA). Analyses were performed using a FACSVerse (Becton Dickinson, Franklin Lakes, NJ, USA).

\subsection{Chondrogenic Differentiation of hDPSCs}

A pellet culture system was used for chondrogenic differentiation. The hDPSCs were trypsinized and resuspended in chondrogenic medium consisting of high-glucose DMEM supplemented with $50 \mu \mathrm{g} / \mathrm{mL}$ ascorbic acid 2-phosphate (Sigma-Aldrich, St. Louis, MO, USA), $40 \mu \mathrm{g} / \mathrm{mL}$ 1-proline (Sigma-Aldrich), $1 \mu \mathrm{M}$ dexamethasone (Sigma-Aldrich), 10\% ITS ${ }^{+}$Pre-mix Tissue Culture Supplement (Becton Dickinson), and $10 \mu \mathrm{g} / \mathrm{mL}$ transforming growth factor beta 1 (TGF- $\beta 1$; Peprotech, Rocky Hill, NJ, USA). To make a pellet, aliquots of hDPSCs $\left(5 \times 10^{5}\right.$ cells) were centrifuged at $500 \times g$ for 5 min in $15-\mathrm{mL}$ conical tubes. Pellets were incubated in $5 \%$ humidified $\mathrm{CO}_{2}$ at $37^{\circ} \mathrm{C}$. The medium was changed every 2 to 3 days, and pellets were harvested at $3,5,7,10$, and 14 days of culture.

\subsection{Cell Viability Assay}

Cell viability was determined using the EZ-Cytox kit (Daeil Lab Service, Seoul, Korea), based on the water-soluble tetrazolium salt (WST) method. The hDPSCs were seeded in 96-well plates at a density of $1 \times 10^{4}$ cells per well with various concentrations of $E$. faecium L-15 extract $(0,10,25,50,100$, and $200 \mu \mathrm{g} / \mathrm{mL}$ ) for $72 \mathrm{~h}$. Then, WST solution was added to each well. The mixture was incubated for $30 \mathrm{~min}$ at $37^{\circ} \mathrm{C}$. The absorbance of each well was measured at $450 \mathrm{~nm}$ with the Emax Plus Microplate reader (Molecular Devices, Sunnyvale, CA, USA).

\subsection{Real-Time Quantitative Polymerase Chain Reaction (PCR)}

Three independent replicates were conducted with two different batches of cells (A and B) at passage 6 and 7 (A passage 6, A passage 7, and B passage 6). Total RNA was extracted from pellets using the PureLink ${ }^{\mathrm{TM}}$ RNA Mini kit (Life Technologies, Camarillo, CA, USA). The synthesis of cDNA was performed using M-MLV reverse transcriptase (Cosmogenetech, Seoul, Korea) according to the manufacturer's instructions. Real-time PCR was performed using SYBR Pre-mix Ex Taq ${ }^{\mathrm{TM}}$ II (Takara, Tokyo, Japan) and the 7500 Real-Time PCR System (Applied Biosystems, Carlsbad, CA, USA). The primers used are listed in Supplementary Data (Table S3). The PCR reaction was performed for $30 \mathrm{~s}$ at $95^{\circ} \mathrm{C}$, followed by 40 amplification cycles of $5 \mathrm{~s}$ at $95^{\circ} \mathrm{C}$ and $34 \mathrm{~s}$ at $60^{\circ} \mathrm{C}$. The comparative $\mathrm{C}_{\mathrm{T}}$ method was used to measure the level of expression. Glyceraldehyde 3-phophate dehydrogenase $(G A P D H)$ was used as a housekeeping gene for normalization.

\subsection{Quantitative Analysis of Glycosaminoglycan (GAG)}

Four pellets from each group were used for GAG quantification. The amount of sulfated GAG was quantified using the Blyscan ${ }^{\mathrm{TM}}$ glycosaminoglycan assay (Biocolor, Carrickfergus, UK) according to the manufacturer's instructions. Briefly, pellets were digested for $12 \mathrm{~h}$ in papain extraction reagent at $65^{\circ} \mathrm{C}$. The lysate was mixed with Blyscan dye reagent and then with dissociation reagent. The absorbance at $525 \mathrm{~nm}$ was measured using the Emax Plus microplate reader (Molecular Devices). The relative cell number was determined by quantifying the total DNA using a Quant-iT ${ }^{\mathrm{TM}}$ PicoGreen $^{\mathrm{TM}}$ dsDNA assay kit (Thermo Scientific, Waltham, MA, USA) according to the manufacturer's instructions. GAG content was normalized by DNA content.

\subsection{Quantification of Proteoglycan Content}

The hDPSCs were differentiated into chondrocytes using chondrogenic differentiation medium and E. faecium L-15 extract for two weeks. Pellets were fixed with $4 \%$ paraformaldehyde for $30 \mathrm{~min}$. Pellets were washed with phosphate-buffered saline (PBS) and incubated with alcian blue staining solution (Merck, Darmstadt, Germany) in the dark for $1 \mathrm{~h}$ at room temperature. Pellets were rinsed 
three times with $\mathrm{ddH}_{2} \mathrm{O}$ to neutralize the acidity. For quantitative analyses, alcian blue-stained cells were dissolved in $6 \mathrm{M}$ guanidine hydrochloride (Sigma-Aldrich) for $6 \mathrm{~h}$. The absorbance of the solubilized solution was measured at $650 \mathrm{~nm}$.

\subsection{Statistical Analysis}

Results are presented as mean \pm SD. Data were analyzed using one-way analysis of variance (ANOVA) followed by Dunnett's test and two-way ANOVA with GraphPad Prism V5.0 software (GraphPad Software, La Jolla, CA, USA). $p<0.05$ was defined as statistical significance.

\section{Conclusions}

We cultured the hDPSCs using chondrogenic differentiation medium in combination with L-15 extract and observed the effect of L-15 extract on chondrogenic differentiation. The expression of SOX9, COL2A1, ACAN, COL10A1, RUNX2, and MMP13, markers of chondrogenic differentiation, was analyzed and the amount of GAG or proteoglycan, an extracellular matrix of chondrocytes, was enumerated. The LET group showed that the markers of chondrogenic differentiation were over-expressed compared to the control group. In particular, these markers were over-expressed in the early stage. The amounts of GAG and proteoglycan were also found to be highly expressed in the LET group at all dates. This study suggests that L-15 extract promotes chondrogenic differentiation.

Supplementary Materials: Supplementary materials can be found at http:/ /www.mdpi.com/1422-0067/20/3/ $624 / \mathrm{s} 1$.

Author Contributions: H.K. and S.P. designed the experiment under the supervision of J.S. and S.R. H.K. and S.R. wrote the manuscript. H.K. and K.K. performed the experiments and analyzed the data. H.K. and S.P. performed the literature research. H.K., S.P., and S.R. designed the research template. S.K. edited and revised the manuscript based on a non-disclosure research agreement between Middle Tennessee State University and Neoregen Biotech. All authors discussed the drafts and approved the final manuscript for publication.

Acknowledgments: This study was supported by a grant from the National Research Foundation of Korea (NRF-2016R1D1A1B03931864) and by the Technology Development Program (S2423830 and S2519744) funded by the Ministry of SMEs and Startups (MSS, Korea).

Conflicts of Interest: The authors declare no conflict of interest. The founding sponsors had no role in the design of the study; in the collection, analyses, or interpretation of data; in the writing of the manuscript, and in the decision to publish the results. NeoRegen Biotech Co., Ltd. supported the salary for J.S. and S.P.

\section{References}

1. Bornes, T.D.; Adesida, A.B.; Jomha, N.M. Mesenchymal stem cells in the treatment of traumatic articular cartilage defects: A comprehensive review. Arthritis Res. Ther. 2014, 16, 432. [CrossRef]

2. Caldwell, K.L.; Wang, J. Cell-based articular cartilage repair: The link between development and regeneration. Osteoarthritis Cartil. 2015, 23, 351-362. [CrossRef]

3. Gillogly, S.D.; Arnold, R.M. Autologous chondrocyte implantation and anteromedialization for isolated patellar articular cartilage lesions: 5- to 11-year follow-up. Am. J. Sports Med. 2014, 42, 912-920. [CrossRef]

4. Kwak, S.K.; Kern, B.S.; Ferkel, R.D.; Chan, K.W.; Kasraeian, S.; Applegate, G.R. Autologous chondrocyte implantation of the ankle: 2- to 10-year results. Am. J. Sports Med. 2014, 42, 2156-2164. [CrossRef]

5. Ahmed, T.A.; Hincke, M.T. Mesenchymal stem cell-based tissue engineering strategies for repair of articular cartilage. Histol. Histopathol. 2014, 29, 669-689. [CrossRef]

6. Johnson, K.; Zhu, S.; Tremblay, M.S.; Payette, J.N.; Wang, J.; Bouchez, L.C.; Meeusen, S.; Althage, A.; Cho, C.Y.; $\mathrm{Wu}, \mathrm{X}$; i et al. A stem cell-based approach to cartilage repair. Science 2012, 336, 717-721. [CrossRef]

7. Lee, W.Y.; Wang, B. Cartilage repair by mesenchymal stem cells: Clinical trial update and perspectives. J. Orthop. Transl. 2017, 9, 76-88. [CrossRef]

8. Sharpe, P.T. Dental mesenchymal stem cells. Development 2016, 143, 2273-2280. [CrossRef]

9. Al-Zer, H.; Apel, C.; Heiland, M.; Friedrich, R.E.; Jung, O.; Kroeger, N.; Eichhorn, W.; Smeets, R. Enrichment and Schwann Cell Differentiation of Neural Crest-derived Dental Pulp Stem Cells. In Vivo 2015, 29, 319-326. 
10. Didilescu, A.C.; Rusu, M.C.; Nini, G. Dental pulp as a stem cell reservoir. Rom. J. Morphol. Embryol. 2013, 54, 473-478.

11. Guimaraes, E.T.; Cruz Gda, S.; Almeida, T.F.; Souza, B.S.; Kaneto, C.M.; Vasconcelos, J.F.; Santos, W.L.; Santos, R.R.; Villarreal, C.F.; Soares, M.B. Transplantation of stem cells obtained from murine dental pulp improves pancreatic damage, renal function, and painful diabetic neuropathy in diabetic type 1 mouse model. Cell Transpl. 2013, 22, 2345-2354. [CrossRef]

12. Ellis, K.M.; O'Carroll, D.C.; Lewis, M.D.; Rychkov, G.Y.; Koblar, S.A. Neurogenic potential of dental pulp stem cells isolated from murine incisors. Stem Cell Res. Ther. 2014, 5, 30. [CrossRef]

13. Bojic, S.; Volarevic, V.; Ljujic, B.; Stojkovic, M. Dental stem cells-Characteristics and potential. Histol. Histopathol. 2014, 29, 699-706. [CrossRef]

14. Fijan, S. Microorganisms with claimed probiotic properties: An overview of recent literature. Int. J. Environ. Res. Public Health 2014, 11, 4745-4767. [CrossRef]

15. Liu, H.; Yang, C.; Jing, Y.; Li, Z.; Zhong, W.; Li, G. Ability of lactic acid bacteria isolated from mink to remove cholesterol: In vitro and in vivo studies. Can. J. Microbiol. 2013, 59, 563-569. [CrossRef]

16. Ispirli, H.; Demirbas, F.; Dertli, E. Characterization of functional properties of Enterococcus faecium strains isolated from human gut. Can. J. Microbiol. 2015, 61, 861-870. [CrossRef]

17. Park, J.E.; Oh, S.H.; Cha, Y.S. Lactobacillus plantarum LG42 isolated from gajami sik-hae inhibits adipogenesis in 3T3-L1 adipocyte. Biomed. Res. Int. 2013, 2013, 460927. [CrossRef]

18. Park, O.J.; Kim, J.; Yang, J.; Yun, C.H.; Han, S.H. Enterococcus faecalis Inhibits Osteoblast Differentiation and Induces Chemokine Expression. J. Endod. 2015, 41, 1480-1485. [CrossRef]

19. Mansour, N.M.; Heine, H.; Abdou, S.M.; Shenana, M.E.; Zakaria, M.K.; El-Diwany, A. Isolation of Enterococcus faecium NM113, Enterococcus faecium NM213 and Lactobacillus casei NM512 as novel probiotics with immunomodulatory properties. Microbiol. Immunol. 2014, 58, 559-569. [CrossRef]

20. Abdhul, K.; Ganesh, M.; Shanmughapriya, S.; Kanagavel, M.; Anbarasu, K.; Natarajaseenivasan, K. Antioxidant activity of exopolysaccharide from probiotic strain Enterococcus faecium (BDU7) from Ngari. Int. J. Biol. Macromol. 2014, 70, 450-454. [CrossRef]

21. Marcacci, M.; Filardo, G.; Kon, E. Treatment of cartilage lesions: What works and why? Injury 2013, 44, S11-S15. [CrossRef]

22. Jevotovsky, D.S.; Alfonso, A.R.; Einhorn, T.A.; Chiu, E.S. Osteoarthritis and stem cell therapy in humans: A systematic review. Osteoarthritis Cartilage 2018. [CrossRef] [PubMed]

23. Marmotti, A.; Mattia, S.; Castoldi, F.; Barbero, A.; Mangiavini, L.; Bonasia, D.E.; Bruzzone, M.; Dettoni, F.; Scurati, R.; Peretti, G.M. Allogeneic Umbilical Cord-Derived Mesenchymal Stem Cells as a Potential Source for Cartilage and Bone Regeneration: An In Vitro Study. Stem Cells Int. 2017, 2017, 1732094. [CrossRef]

24. Goldring, M.B.; Goldring, S.R. Articular cartilage and subchondral bone in the pathogenesis of osteoarthritis. Ann. N. Y. Acad. Sci. 2010, 1192, 230-237. [CrossRef]

25. Studer, D.; Millan, C.; Ozturk, E.; Maniura-Weber, K.; Zenobi-Wong, M. Molecular and biophysical mechanisms regulating hypertrophic differentiation in chondrocytes and mesenchymal stem cells. Eur. Cell Mater. 2012, 24, 118-135. [CrossRef] [PubMed]

26. Shiomi, T.; Lemaitre, V.; D'Armiento, J.; Okada, Y. Matrix metalloproteinases, a disintegrin and metalloproteinases, and a disintegrin and metalloproteinases with thrombospondin motifs in non-neoplastic diseases. Pathol. Int. 2010, 60, 477-496. [CrossRef]

27. Roach, H.I.; Yamada, N.; Cheung, K.S.; Tilley, S.; Clarke, N.M.; Oreffo, R.O.; Kokubun, S.; Bronner, F. Association between the abnormal expression of matrix-degrading enzymes by human osteoarthritic chondrocytes and demethylation of specific CPG sites in the promoter regions. Arthritis Rheumatol. 2005, 52, 3110-3124. [CrossRef]

28. Aref-Eshghi, E.; Liu, M.; Harper, P.E.; Dore, J.; Martin, G.; Furey, A.; Green, R.; Rahman, P.; Zhai, G. Overexpression of MMP13 in human osteoarthritic cartilage is associated with the SMAD-independent TGF-beta signalling pathway. Arthritis Res. Ther. 2015, 17, 264. [CrossRef]

29. Neuhold, L.A.; Killar, L.; Zhao, W.; Sung, M.L.; Warner, L.; Kulik, J.; Turner, J.; Wu, W.; Billinghurst, C.; Meijers, T.; et al. Postnatal expression in hyaline cartilage of constitutively active human collagenase-3 (MMP-13) induces osteoarthritis in mice. J. Clin. Investig. 2001, 107, 35-44. [CrossRef]

30. Wang, M.; Sampson, E.R.; Jin, H.; Li, J.; Ke, Q.H.; Im, H.J.; Chen, D. MMP13 is a critical target gene during the progression of osteoarthritis. Arthritis Res. Ther. 2013, 15, R5. [CrossRef] 
31. Cao, Z.; Bai, Y.; Liu, C.; Dou, C.; Li, J.; Xiang, J.; Zhao, C.; Xie, Z.; Xiang, Q.; Dong, S. Hypertrophic differentiation of mesenchymal stem cells is suppressed by xanthotoxin via the p38MAPK/HDAC4 pathway. Mol. Med. Rep. 2017, 16, 2740-2746. [CrossRef] [PubMed]

32. Sutherland, A.J.; Converse, G.L.; Hopkins, R.A.; Detamore, M.S. The bioactivity of cartilage extracellular matrix in articular cartilage regeneration. Adv. Healthc. Mater. 2015, 4, 29-39. [CrossRef] [PubMed]

33. Wylie, J.D.; Hartley, M.K.; Kapron, A.L.; Aoki, S.K.; Maak, T.G. What is the effect of matrices on cartilage repair? A systematic review. Clin. Orthop. Relat. Res. 2015, 473, 1673-1682. [CrossRef] [PubMed]

34. Kiyotake, E.A.; Beck, E.C.; Detamore, M.S. Cartilage extracellular matrix as a biomaterial for cartilage regeneration. Ann. N. Y. Acad. Sci. 2016, 1383, 139-159. [CrossRef] [PubMed]

35. Barbosa, J.; Borges, S.; Teixeira, P. Selection of potential probiotic Enterococcus faecium isolated from Portuguese fermented food. Int. J. Food Microbiol. 2014, 191, 144-148. [CrossRef] [PubMed]

36. Cardenas, N.; Arroyo, R.; Calzada, J.; Peiroten, A.; Medina, M.; Rodriguez, J.M.; Fernandez, L. Evaluation of technological properties of Enterococcus faecium CECT 8849, a strain isolated from human milk, for the dairy industry. Appl. Microbiol. Biotechnol. 2016, 100, 7665-7677. [CrossRef] [PubMed]

37. Park, D.Y.; Ahn, Y.T.; Huh, C.S.; Jeon, S.M.; Choi, M.S. The inhibitory effect of Lactobacillus plantarum KY1032 cell extract on the adipogenesis of 3T3-L1 Cells. J. Med. Food 2011, 14, 670-675. [CrossRef]

38. Tong, Z.; Ma, J.; Tan, J.; Huang, L.; Ling, J. Effects of inactivated Enterococcus faecalis on the proliferation and osteogenic induction of osteoblasts. Mol. Med. Rep. 2016, 14, 5125-5133. [CrossRef]

(C) 2019 by the authors. Licensee MDPI, Basel, Switzerland. This article is an open access article distributed under the terms and conditions of the Creative Commons Attribution (CC BY) license (http://creativecommons.org/licenses/by/4.0/). 